\title{
Os melhores atletas nos escalões de formação serão igualmente os melhores atletas no escalão sénior? Análise centrada nos ran- kings femininos das diferentes disciplinas do Atletismo ao longo das últimas duas décadas em Portugal
}

\author{
Nélson Brito \\ António M. Fonseca \\ Ramiro Rolim
}

https://doi.org/10.5628/rpcd.04.01.17

\section{RESUMO}

Actualmente, a prática desportiva federada de crianças e jovens está fortemente perpassada e indexada a uma única referência: a vitória, o sucesso desportivo. Todavia, será que o êxito desportivo obtido em idades jovens derivará em sucesso na idade adulta? Face a esta dúvida e dado que a realização de estudos neste domínio tem sido escassa, decidimos investigar o percurso das atletas femininas que se encontravam nos primeiros cinco lugares nos rankings nacionais das diversas especialidades do atletismo, nos escalões de formação (infantil, iniciado e juvenil), entre os anos 1986 a 1990 inclusive. Neste sentido, foram realizadas análises retrospectivas do percurso de trezentas e vinte e nove atletas até ao escalão de sénior e até à época de 2002. Embora seja necessário aguardar mais alguns anos para se conhecer, em toda a sua extensão, o percurso destas atletas, os principais resultados obtidos permitem evidenciar que, até ao momento, muito do investimento feito em idades jovens tem-se revelado pouco rentável ou mesmo infrutífero. Constatou-se que apenas um reduzido número de jovens atletas conseguiu prolongar a sua carreira desportiva até ao escalão sénior com uma presença assídua entre as cinco melhores dos rankings. Também se verificou que, quanto mais baixo é o escalão considerado, menor é o número de atletas que confirma, no escalão sénior, o êxito obtido no escalão de formação.

Palavras-chave: atletismo, percurso desportivo, iniciação e especialização precoce, evolução nos rankings.
Faculdade de Ciências do Desporto e de Educação Física

Universidade do Porto, Portugal

ABSTRACT

Will best athletes as youngsters be equally best as adults?

Actually, children and youngsters formal sports participation within Sports Federations is pushed towards a "single" reference: victory or sports success. Though, will it be that the success obtained in young ages will result in success in the adult age? Retrospective and forecasting studies in this domain are scarce, and in Portugal non-existent. Therefore, the main purpose of this paper was to study, retrospectively, women's career in the top five (Portuguese rankings), in the junior stage (under 13, 15 and 17 years old), between 1986 and 1990. A descriptive and retrospective analysis was conducted on three hundred and twenty-nine athletes till the senior stage. Main results suggest that a lot of the investment done has not been translated in sucess, at least till now. Only a small number of young athletes continued their sport career to the senior stage keeping up with the best ranked ones. The lower the age, the lower is the likelihood of confirming in the senior years the success obtained in the formative stage.

Key Words: athletics, sports career, early initiation and early specialization, ranking progression. 


\section{INTRODUÇÃO}

O treino desportivo de crianças e jovens e a dinâmica formativa implementada no desporto escolar e nos clubes são vectores fundamentais para a proliferação e desenvolvimento da prática desportiva entre a população jovem, bem como para a sobrevivência de qualquer desporto.

Em alguns desportos existe mesmo a convicção de que a excelência só pode ser alcançada quando, durante os escalões de formação, a aprendizagem de uma modalidade, o treino e a competição são correctamente perspectivados e concretizados.

Sendo reconhecida a importância dos factores genéticos e do envolvimento no rendimento desportivo (5), é frequentemente sublinhado que um leque diversificado de experiências desportivas, vividas durante o processo de crescimento e desenvolvimento do praticante, parece relacionar-se positivamente com a obtenção de altos rendimentos na idade adulta $(2,7,13,21,24)$.

Face a este quadro lógico-empírico, será razoável pugnar para que o processo de formação e de treino em idades jovens procure fomentar e proporcionar, em particular durante o estádio de treino de base, uma grande diversidade de experiências motoras. Não obstante, é comum observar-se que o treino nas etapas iniciais do processo de formação desportiva continua a ser orientado à imagem do treino do atleta adulto, ou seja, perspectivado segundo a lógica do rendimento e da obtenção de resultados significativos tão depressa quanto possível. Obviamente que, no caso do desporto jovem, a opção por trajectos desta natureza vai desaguar numa preparação precocemente especializada, levando, por um lado, à redução da diversidade de experiências e, por outro, ao aumento exagerado das cargas de treino. Se assim não fosse, a obtenção "imediata" de resultados desportivos de qualidade por parte dos jovens ficaria comprometida.

Apesar da incerteza e das eventuais consequências nefastas que este modelo de formação pode produzir, ele continua a encontrar legitimidade e a povoar a mente de inúmeros e fieis seguidores. Segundo esta lógica redutora, o futuro desportivo dos jovens parece ser bem menos importante que o presente. Acrescente-se, ainda, que as modalidades individuais, dadas as suas características intrínsecas, são aquelas que mais evidenciam esta tendência (uma precoce preparação unilateral e especializada). Perante cenários desta natureza, cada vez mais habituais, urge encontrar respostas consistentes da parte dos adultos que enquadram técnica e desportivamente os jovens. Exige-se o total respeito pela sua integridade física e mental. Impõe-se o respeito pelas suas opções. Requer-se um enquadramento ético e pedagógico da formação ministrada. Preceitua-se que o jovem praticante seja visto como tal e não como «um adulto em miniatura», pois ele tem características e necessidades próprias, as quais não podem ser encaradas como uma simples redução das apresentadas ao adulto.

As respostas para estes desafios, não sendo óbvias, terão que passar, certamente, por uma sólida formação técnica, pedagógica e ética dos treinadores. Deste modo, é hoje consensualmente aceite que, quando se trata de crianças e jovens, a preparação desportiva deve ir ao encontro das suas características de desenvolvimento, impondo-se, por via disso, uma delimitação consciente das diferentes etapas desse desenvolvimento, em que cada uma dessas etapas deve, respeitando o jovem atleta, conciliar, adequada e equilibradamente, a definição de objectivos, a delimitação dos conteúdos e a selecção criteriosa dos meios e métodos de treino a utilizar em cada momento do seu processo de formação desportiva. Só assim se conseguirá elevar o número de praticantes e, sobretudo, fixar os jovens de forma duradoura à prática de uma qualquer modalidade.

Face ao quadro de problemas comuns ao desporto jovem e aqui brevemente traçados, há a convicção, no caso do Atletismo, de que os melhores jovens de hoje, por motivos que não cabe aqui apurar, dificilmente se conseguem impor nos escalões superiores, acabando muitos deles por abandonar definitiva e precipitadamente a prática da modalidade.

A este respeito, diferentes autores $(6,9,13,27)$ têm referido não existir certezas quanto à possibilidade de crianças e jovens que se destacam nos escalões de formação, o continuem a fazer na idade adulta. Hahn (13) afirma haver apenas entre 10 a $20 \%$ de probabilidades de encontrar os melhores praticantes dos escalões mais baixos de formação na elite desportiva futura. Por sua vez, Feuillepain (9), num estudo realizado em França, concluiu que as categorias benja- 
mins e infantis raramente alcançam a elite do Atletismo gaulês.

Por outras palavras, interrogamo-nos se serão os jovens que se distinguem pela sua capacidade de rendimento nos escalões de formação aqueles que continuarão a distinguir-se na idade adulta?

Assim, na tentativa de encontrar respostas consistentes para fenómenos desta natureza em Portugal, impõe-se observar, questionar e investigar o percurso desportivo dos praticantes de Atletismo, desde a iniciação até ao apogeu.

Em Portugal e no Atletismo não existem estudos suficientemente profundos e abrangentes onde esta problemática é investigada, havendo um desconhecimento sobre o percurso desportivo dos atletas ao longo da sua vida desportiva.

Face a este quadro, esta investigação centra-se na modalidade de Atletismo e, particularmente, nas provas de pista ao ar livre do sector feminino. Com efeito, em função do problema colocado, pretendemos analisar o percurso das atletas que se encontravam nos primeiros cinco lugares dos rankings (rks) dos escalões de formação (infantis, iniciados e juvenis), entre os anos de 1986 e 1990 inclusive.

\section{METODOLOGIA}

\section{Amostra}

Em função do objectivo definido, foram tomados como elementos de análise os rks nacionais das provas de pista ao ar livre dos escalões de infantil, iniciado e juvenil publicados anualmente nas décadas de oitenta e noventa pela revista portuguesa Atletismo. A amostra foi constituída pela totalidade das atletas do sexo feminino (329) que se encontravam nos primeiros cinco lugares dos rks nacionais de Atletismo, das diferentes provas de pista, nos escalões de formação (infantil, iniciado e juvenil), entre 1986 e 1990. No escalão infantil, num total de duzentos e vinte lugares possíveis dos rks considerados, encontravam-se 132 atletas.

No escalão iniciado, num total de trezentos lugares possíveis dos rks considerados, encontravam-se 149 atletas. Contudo, 36 atletas já haviam ocupado, entre 1986 e 1990, os primeiros cinco lugares dos rks do escalão infantil. Deste modo, o número de atletas a analisar, nos rks do escalão iniciado, reduziu-se para 113.
No escalão juvenil, num total de trezentos e cinquenta lugares possíveis dos rks considerados, encontravam-se 133 atletas. Neste escalão, verificou-se uma situação idêntica à anterior; ou seja, 49 atletas já haviam ocupado, entre 1986 e 1990, os primeiros cinco lugares dos rks dos escalões precedentes (infantil e iniciado). Assim, o número de atletas a analisar nos rks do escalão juvenil circunscreveu-se apenas a 84 .

\section{Procedimento de análise dos dados}

Delimitada a amostra, elaborou-se uma base de dados para cada escalão, organizada em colunas (campos) e linhas (registos). Nas colunas constava o nome da atleta, a data de nascimento e o ano da(s) prova(s). Às linhas correspondia o percurso ou evolução longitudinal de cada atleta nos rks das provas realizadas.

Por forma a facilitar a introdução e o respectivo tratamento dos dados, atribuímos previamente uma referência numérica às diferentes provas de pista dos diferentes rks em análise.

Em seguida, registámos o percurso de cada atleta nos primeiros cinco lugares dos rks dos diferentes escalões até ao ano 2000 .

Pelo facto de constatarmos que, para os escalões estudados, as provas que compõem os seus habituais quadros competitivos são diferentes ${ }^{1}$, e que estas têm sofrido alterações ao longo dos anos em análise, optou-se por agrupar as diferentes provas de acordo com as suas características comuns, formando sete agrupamentos: (i) velocidade, (ii) meio fundo e fundo, (iii) saltos verticais, (iv) saltos horizontais, (v) lançamentos, (vi) marcha e (vii) provas combinadas. Uma vez agrupadas as atletas pelos diferentes escalões e pelos agrupamentos de provas, procedemos à análise dos dados.

Em todos os agrupamentos de provas e para todos os escalões, procurámos analisar o número de atletas que:

a) se encontravam nos lugares em estudo ${ }^{2}$;

b) ainda não apresentavam a idade correspondente ao escalão em que se encontravam nos rks;

c) se encontravam em dois ou mais agrupamentos de provas simultaneamente;

d) se encontravam nos rks pela primeira vez entre 1986 e 1990; 
e) surgiam nos primeiros cinco lugares dos rks dos escalões seguintes;

f) surgiam, no mesmo agrupamento de provas, nos primeiros cinco lugares dos rks dos escalões subsequentes.

Devido ao desconhecimento sobre esta matéria, assumimos o nosso estudo como exploratório, no sentido de dar a conhecer sistematizada e ordenadamente dados que, até ao momento, se encontram dispersos. Ademais, através da interpretação dos resultados obtidos pretendemos proceder a uma compreensão mais objectiva do percurso das atletas no Atletismo português e, eventualmente, trazer à luz informações relevantes para os treinadores e demais agentes desportivos. Por outro lado, em função do nosso conhecimento profundo da realidade do Atletismo português, não deixaremos de indagar e apontar eventuais causas que, no nosso entendimento, possam constituir a génese dos resultados encontrados.

\section{RESULTADOS}

\section{Escalão infantil}

Nos 220 lugares em estudo encontravam-se 132 atletas (28 encontravam-se, simultaneamente, entre os primeiros cinco lugares dos rks de dois ou mais agrupamentos de provas). A percentagem de atletas nos diferentes agrupamentos de provas situa-se entre $72 \%$ (saltos verticais) e $88 \%$ (saltos horizontais) (cfr. figura 1 ).

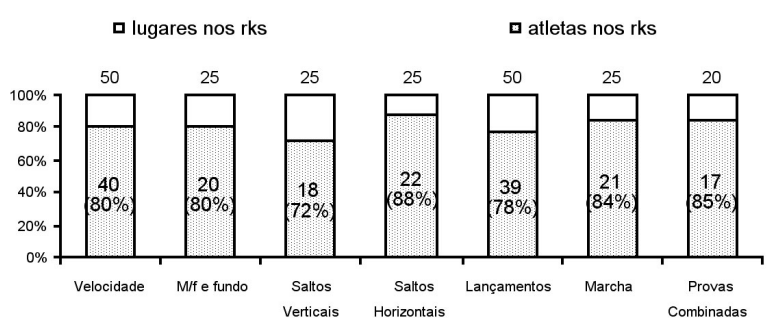

Figura 1 - Distribuição pelos diferentes agrupamentos de provas do número de atletas que se encontravam nos primeiros cinco lugares dos rks do escalão infantil e sua correlação com o número de lugares disponíveis.

Analisando o percurso das 132 atletas infantis nos rks dos escalões superiores, verificámos que nos primeiros cinco lugares dos escalões iniciado, juvenil e sénior surgem respectivamente 55, 36 e 15 atletas (cfr. quadro 1).
Quadro 1 - Escalão infantil: número de atletas que surgiram nos primeiros cinco lugares dos rks dos escalões subsequentes.

\begin{tabular}{|c|c|c|c|c|}
\hline Posição & $\begin{array}{l}\text { Escalão } \\
\text { infantil }\end{array}$ & $\begin{array}{l}\text { Escalão } \\
\text { iniciado }\end{array}$ & $\begin{array}{l}\text { Escalão } \\
\text { juvenil }\end{array}$ & $\begin{array}{l}\text { Escalão } \\
\text { sénior }\end{array}$ \\
\hline $\begin{array}{l}\text { Unicamente } \\
\text { num grupo }\end{array}$ & 104 & $35(33,7 \%)$ & $19(18,2 \%)$ & $10(9,6 \%)$ \\
\hline $\begin{array}{l}\text { Simultaneamente } \\
\text { em } 2 \text { ou mais grupos }\end{array}$ & S & $20(71,4 \%)$ & $17(60,7 \%)$ & $5(17,8 \%)$ \\
\hline Total & 132 & $55[41,6 \%)$ & $36[27,2 \%]$ & $15(11,3 \%)$ \\
\hline
\end{tabular}

Observando, para cada agrupamento de provas, a percentagem de atletas que surge nos primeiros cinco lugares dos rks dos escalões superiores, independentemente do agrupamento em que viriam a surgir, verificámos que os valores encontrados estão compreendidos entre (cfr. figura 2 ):

a) $19 \%$ (marcha) e $82 \%$ (provas combinadas), no escalão de iniciados;

b) $0 \%$ (marcha) e $53 \%$ (provas combinadas), no escalão juvenil;

c) $0 \%$ (marcha) e $29 \%$ (provas combinadas), no escalão sénior.

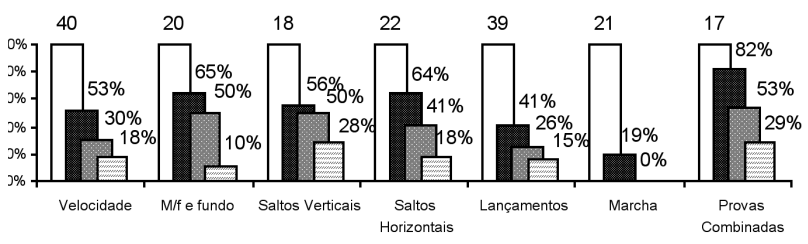

Figura 2 - Primeiros cinco lugares dos rks do escalão infantil: percentagem de atletas que viriam a ocupar os primeiros cinco lugares dos rks do escalão iniciado, juvenil e sénior.

Tendo em consideração a progressão dentro do mesmo agrupamento de provas (cfr. figura 3 ), verificámos que a percentagem de atletas que surge nos primeiros cinco lugares dos rks dos escalões superiores está compreendida entre:

a) $19 \%$ (marcha) e $60 \%$ (meio-fundo e fundo, no escalão de iniciados; 
b) $0 \%$ (marcha) e $45 \%$ (meio-fundo e fundo), no escalão juvenil;

c) $0 \%$ (marcha) e $17 \%$ (saltos verticais), no escalão sénior.

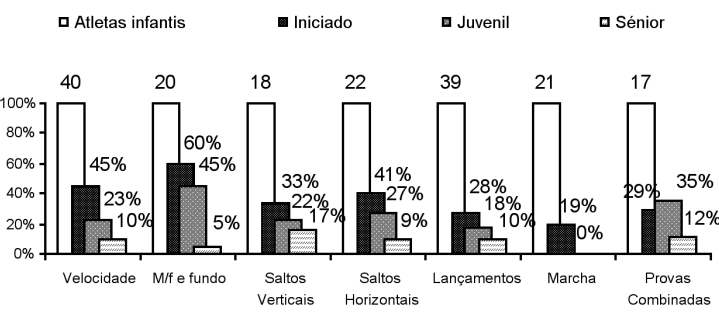

Figura 3 - Primeiros cinco lugares dos rks do escalão infantil: percentagem de atletas que viriam a ocupar, no mesmo agrupamento de provas, os primeiros cinco lugares dos rks do escalão iniciado, juvenil e sénior.

\section{Escalão iniciado}

Nos 300 lugares em estudo encontravam-se 149 atletas. Duas atletas ainda não apresentavam a idade cronológica correspondente a este escalão.

A percentagem de atletas nos diferentes agrupamentos de provas situa-se entre $51 \%$ (lançamentos) e $84 \%$ (provas combinadas) (cfr. figura 4 ).

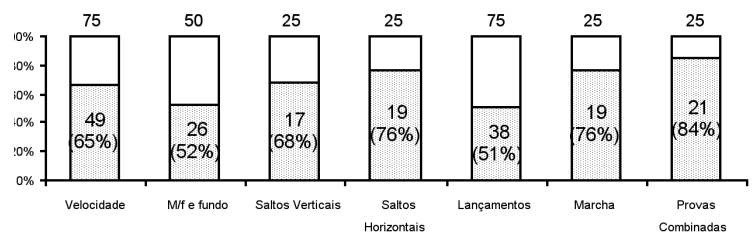

Figura 4 - Distribuição pelos diferentes agrupamentos de provas do número de atletas que se encontravam nos primeiros cinco lugares dos rks do escalão iniciado e sua relação com o número de lugares disponíveis.

Do total das atletas:

a) 36 já se encontravam, enquanto infantis, entre 1986 e 1990, nos primeiros cinco lugares;

b) 113 surgiram pela primeira vez nesse período nos primeiros cinco lugares.

Das 113 atletas, 18 encontravam-se simultaneamente entre os primeiros cinco lugares dos rks de dois ou mais agrupamentos de provas.
Analisando o percurso das 113 atletas nos rks dos escalões superiores, verificámos que surgem nos primeiros cinco lugares dos escalões juvenil e sénior 44 e 15 atletas, respectivamente (cfr. quadro 2 ).

Quadro 2 - Escalão iniciado: número de atletas que surgiram nos primeiros cinco lugares dos rks dos escalões subsequentes.

\begin{tabular}{lccc} 
Posição & $\begin{array}{r}\text { Escalão } \\
\text { iniciado }\end{array}$ & $\begin{array}{c}\text { Escalão } \\
\text { juvenil }\end{array}$ & $\begin{array}{c}\text { Escalão } \\
\text { sénior }\end{array}$ \\
\hline $\begin{array}{l}\text { Unicamente } \\
\text { num agrupamento }\end{array}$ & 95 & $33(34,7 \%)$ & $10(10,5 \%)$ \\
\hline $\begin{array}{l}\text { Simultaneamente } \\
\text { em 2 ou mais agrupamentos }\end{array}$ & 18 & $11(61,1 \%)$ & $5(27,8 \%)$ \\
\hline $\begin{array}{l}\text { Total } \\
\text { Obs. }\end{array}$ & $44(38,9 \%)$ & $15(13,27 \%)$ \\
\hline
\end{tabular}

Observando, para cada agrupamento de provas, a percentagem de atletas que surge nos primeiros cinco lugares dos rks dos escalões superiores, independentemente do agrupamento em que viriam a surgir, verificámos que os valores encontrados estão compreendidos entre ( $c f r$. figura 5):

a) $31 \%$ (saltos verticais) e $50 \%$ (marcha), no escalão juvenil;

b) $5 \%$ (meio-fundo e fundo) e $38 \%$ (provas combinadas), no escalão sénior.

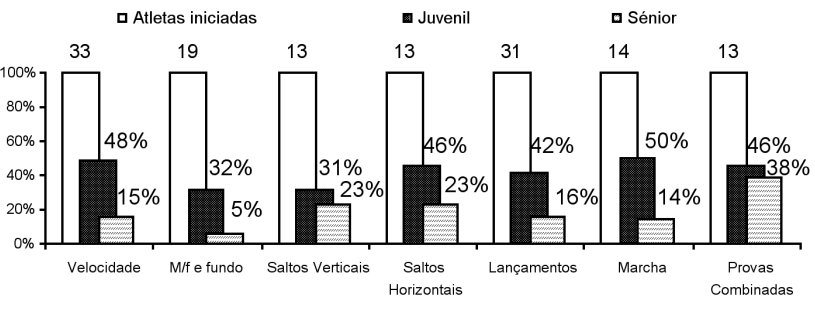

Figura 5 - Primeiros cinco lugares dos rks do escalão iniciado: percentagem de atletas que viriam a ocupar os primeiros cinco lugares dos rks do escalão juvenil e sénior.

Tendo em consideração a progressão dentro do mesmo agrupamento de provas, verificámos que a percentagem de atletas que surge nos primeiros 
cinco lugares dos rks dos escalões superiores está compreendida:

a) para o escalão juvenil, entre $16 \%$ (meio-fundo e fundo) e $50 \%$ (marcha);

b) para o escalão sénior, entre $5 \%$ (meio-fundo e fundo) e $23 \%$ (provas combinadas) (cfr. figura 6 ).

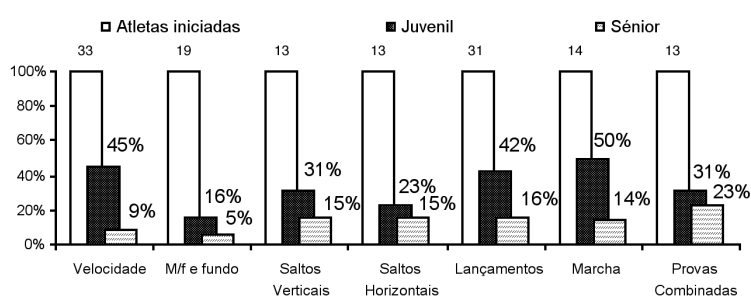

Figura 6 - Primeiros cinco lugares dos rks do escalão iniciado: percentagem de atletas que viriam a ocupar, no mesmo grupo de provas, os primeiros cinco lugares dos rks do escalão juvenil e sénior.

\section{Escalão juvenil}

Nos 350 lugares em estudo encontravam-se 133 atletas. Trinta e cinco atletas ainda não apresentavam a idade correspondente a este escalão.

A percentagem de atletas nos diferentes agrupamentos de provas situa-se entre $38 \%$ (velocidade) e $64 \%$ (provas combinadas) (cfr. figura 7 ).

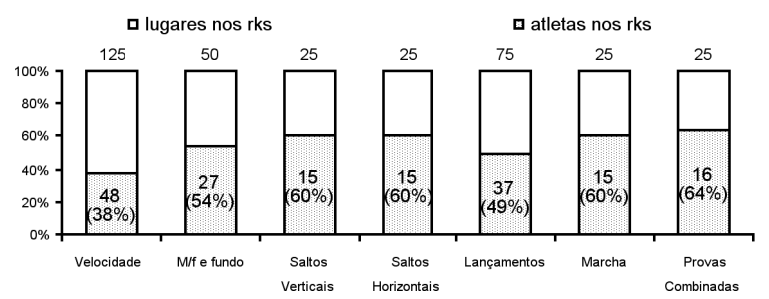

Figura 7 - Distribuição pelos diferentes agrupamentos de provas do número de atletas que se encontravam nos primeiros cinco lugares dos rks do escalão juvenil e sua relação com o número de lugares disponíveis.

Do total das atletas:

a) 49 já se encontravam, enquanto infantis e/ou iniciadas, entre 1986 e 1990, nos primeiros cinco lugares dos rks; b) 84 surgiram pela primeira vez nesse período nos primeiros cinco lugares dos rks, sendo todas juvenis.

Das 84 atletas que surgem nos 5 primeiros lugares dos rks em juvenis, 14 encontravam-se simultaneamente entre os primeiros cinco lugares dos rks de dois ou mais agrupamentos de provas.

Analisando o percurso das 84 atletas nos rks dos escalões superiores, verificámos que 22 surgem nos primeiros cinco lugares do escalão sénior ( $c f r$. quadro 3 ).

Quadro 3 - Escalão juvenil: número de atletas que surgiram nos primeiros cinco lugares dos rks do escalão sénior.

\begin{tabular}{lcc} 
Posição & $\begin{array}{c}\text { Escalão } \\
\text { juvenil }\end{array}$ & $\begin{array}{c}\text { Escalão } \\
\text { sénior }\end{array}$ \\
\hline $\begin{array}{l}\text { Unicamente } \\
\text { num agrupamento }\end{array}$ & 70 & $17(24,3 \%)$ \\
\hline $\begin{array}{l}\text { Simultaneamente } \\
\text { em } 2 \text { ou mais agrupamentos }\end{array}$ & 14 & $5(35,7 \%)$ \\
\hline Total & \multicolumn{3}{c}{84} & $22[26,1 \%)$ \\
\hline Obs. & \multicolumn{3}{l}{ Todas juvenis }
\end{tabular}

Observando, em cada agrupamento de provas, a percentagem de atletas que surge nos primeiros cinco lugares dos rks do escalão sénior, independentemente do agrupamento em que viriam a surgir, verificámos que os valores encontrados estão compreendidos entre 0\% (marcha) e 39\% (velocidade) (cfr. figura 8).

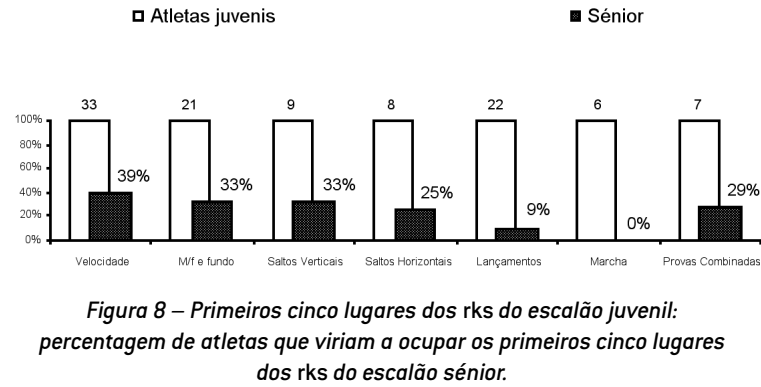

Tendo em consideração a progressão dentro do mesmo agrupamento de provas, verificámos que a 
percentagem de atletas que surge nos primeiros cinco lugares dos rks do escalão sénior está compreendida entre $0 \%$ (marcha e provas combinadas) e $36 \%$ (velocidade) (cfr. figura 9 ).

口 Atletas juvenis

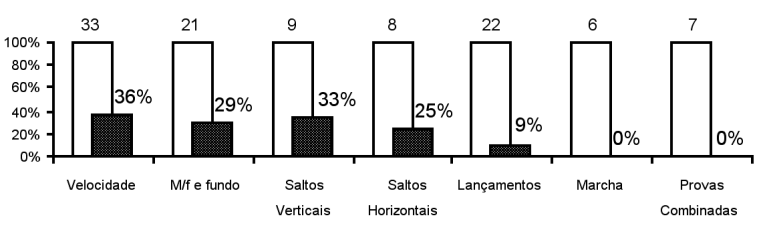

Figura 9 - Primeiros cinco lugares dos rks do escalão juvenil: percentagem de atletas que viriam a ocupar, no mesmo agrupamento de provas, os primeiros cinco lugares dos rks do escalão sénior.

\section{DISCUSSÃO DOS RESULTADOS}

\section{Caracterização dos rks dos diferentes agrupamentos de provas}

Atletas que se encontravam nos rks

Como se constatou nas figuras 1,4 e 7 , à medida que o escalão em estudo é superior, menor é a percentagem de atletas que se encontravam nos primeiros cinco lugares dos rks.

Partindo do pressuposto que os diferentes escalões correspondem a um processo sequencial de especialização no atletismo, os resultados apresentados parecem indiciar que quanto maior é o nível de especialização do treino mais difícil se torna figurar entre os primeiros cinco lugares dos rks. Não obstante, este quadro de diminuição das percentagens de atletas também poderá decorrer, da redução dos níveis de participação desportiva com o aumento da idade (14) e de uma maior flutuabilidade (entenda-se, frequente entrada e saída de atletas jovens da prática do atletismo) nos escalões de infantis e iniciados (24).

A diminuição do número das atletas, nos primeiros 5 lugares dos rks, observada com a passagem de um escalão para o seguinte, não revela qualquer tendência nos diversos agrupamentos de provas, pese embora a existência de algumas diferenças.

Dentre todos os agrupamentos, o das provas combinadas é aquele que apresenta menor tendência descendente. $\mathrm{O}$ carácter multidisciplinar destas provas parece favorecer a ocorrência de um elevado número de atletas neste agrupamento. Ademais, o facto de este ser constituído, em todos os escalões, unicamente por uma prova (provas combinadas) poderá resultar na ocorrência de um maior número de atletas. Pois, em cada ano analisado, cada atleta só pode ocupar, obviamente, uma posição.

Atletas que se encontravam simultaneamente nos rks de dois ou mais agrupamentos de provas Relativamente às atletas que ocupavam os lugares em estudo, verificámos que algumas se encontravam simultaneamente em dois ou mais agrupamentos de provas. Nos escalões infantil, iniciado e juvenil, $21 \%, 16 \%$ e $17 \%$ das atletas estavam, respectivamente, nessa situação.

Sob o ponto de vista da formação desportiva, a percentagem de atletas que se encontravam simultaneamente em dois ou mais agrupamentos de provas, parece-nos ser relativamente reduzida nos escalões infantil e iniciado. Estes dados, em nosso entender, poderão indiciar a adopção antecipada de uma formação desportiva unidireccional, provavelmente centrada na lógica do rendimento.

Ainda que a assunção do treino específico, desde muito cedo, permita ao jovem praticante destacar-se mais rapidamente entre os seus pares, esta opção parece envolver mais riscos que benefícios. É por todos reconhecido que os métodos de treino mais específicos, além de fisiologicamente mais exigentes, são mais monótonos e saturantes. Hipotecar desde logo os meios e métodos mais potentes e específicos, deixará pouca margem de manobra ao treinador para futuras intervenções na dinâmica do treino. No caso concreto do atletismo, o treino desenvolvido durante o estádio de treino de base deve privilegiar, sobretudo, uma actividade diversificada, incluindo as corridas, os saltos e os lançamentos (4, 24). Com efeito, somente após o estádio de treino de base deverá ocorrer uma gradual especialização $(25,26)$.

Percurso das atletas que se encontravam nos primeiros cinco lugares dos rks dos escalões de formação, entre 1986 e 1990 A nossa precaução inicial foi assegurar que o intervalo de tempo considerado no estudo permitisse abranger a entrada das atletas na etapa de alto rendi- 
mento e que estas efectuassem alguns anos de treino nesta etapa. Partimos do pressuposto que o início da etapa de alto rendimento deverá coincidir, para a maioria dos desportos, com o momento em que o organismo atinge a idade adulta, ou seja, quando o processo de crescimento está concretizado e o organismo se encontra em condições de suportar e tolerar cargas de treino compatíveis com o alto rendimento. Com base no exposto, verificámos que no período de tempo contemplado, todas as atletas teriam oportunidade para voltarem a conhecer o sucesso nos rks do escalão sénior.

Analisando nos rks o percurso das atletas em estudo (cfr. quadros 1, 2 e 3), verificámos que apenas $11 \%$ (escalão infantil), $13 \%$ (escalão iniciado) e $26 \%$ (escalão juvenil) surgiram nos primeiros cinco lugares dos rks do escalão sénior.

Face a este quadro, podemos inferir que, as cinco primeiras atletas dos rks dos escalões infantil, iniciado e juvenil, durante 1986 a 1990, não conseguiram confirmar-se nos primeiros 5 lugares dos rks seniores até ao ano 2000. Embora pareçam estranhos, estes resultados não são de todo inesperados. Uma pesquisa conduzida por Garcia e Rolim (11), no âmbito do atletismo com atletas dos escalões de formação (infantil, iniciado e juvenil) considerados os melhores de sempre nas disciplinas de meio-fundo e fundo, permitiu concluir que a quase totalidade dos mesmos abandonou a actividade desportiva antes de atingida a idade sénior ou, se continuavam a competir, revelavam resultados medíocres no escalão sénior.

Uma leitura mais atenta dos referidos quadros (1, 2 e 3), permite salientar que, as atletas posicionadas nos 5 primeiros lugares dos rks durante escalões de formação, em mais de um agrupamento, evidenciavam uma clara e mais fértil evolução longitudinal nos rks (infantis - $17,8 \%$, iniciados $-27,7 \%$ e juvenis - 35,7\%), comparativamente com as que surgiam só num único agrupamento (infantis - 9,6\%, iniciados $10,5 \%$ e juvenis - $24,2 \%$ ).

Embora exista uma manifesta selectividade no acesso às etapas finais deste percurso, sendo relativamente reduzido o número de atletas a revelar aptidões que lhes permitam entrar no alto rendimento (1), estes resultados acrescentam dados importantes para reflexão, nomeadamente sobre a selecção de talentos e sobre a orientação do treino nas etapas iniciais. De qualquer modo, consideram-se manifestamente baixas as percentagens aqui verificadas, particularmente nos escalões infantil e iniciado.

Um dos factores que parece concorrer para a discrepância entre o êxito nos escalões de formação e o sucesso no escalão sénior, é o facto de a prática desportiva das crianças e jovens seguir a lógica do rendimento imediato e estar frequentemente condicionada por apenas uma referência de sucesso - a vitória $^{3}$. Geralmente, o triunfo é apoiado e incentivado por todos os que directa ou indirectamente intervêm no processo desportivo, nomeadamente treinadores, familiares, dirigentes e público em geral. Ignora-se assim, a preocupação com o desenvolvimento a longo prazo. Em consequência, como refere Lima (16), é gerado um quadro de acentuadas pressões sobre os treinadores. Estes, na maioria das vezes, são induzidos a proceder a uma formação desportiva centrada numa especialização precoce, que contribui, segundo este autor, para a eliminação antecipada dos jovens praticantes.

Considerando a existência de inúmeras causas que, ao longo da vida desportiva, vão afastando os jovens do treino (conflitos de interesse, lesões, processos de saturação, transferência para outras modalidades, etc.), torna-se necessário em futuros estudos conhecê-las de modo aprofundado, por forma a melhor compreender este fenómeno e, simultaneamente, procurar inverter a tendência de quebra aqui verificada.

O percurso nos diferentes agrupamentos de provas Analisado comparativamente em cada agrupamento de provas o percurso das atletas em estudo, verificámos que a percentagem de atletas dos escalóes de formação que surgiram nos primeiros cinco lugares dos rks do escalão sénior se encontra compreendida entre 5\% (marcha) e 32\% (provas combinadas). Particularizando, os valores encontram-se compreendidos no escalão:

a) infantil, entre $0 \%$ (marcha) e $29 \%$ (provas combinadas);

b) iniciado, entre $5 \%$ (meio-fundo e fundo) e $38 \%$ (provas combinadas);

c) juvenil, entre $0 \%$ (marcha) e $39 \%$ (velocidade). 
Face a este quadro, podemos inferir que em todos os agrupamentos de provas a maioria das atletas que se encontravam entre as melhores nos rks dos escalões infantil, iniciado e juvenil, durante 1986 a 1990, não conseguiu confirmar no escalão sénior o êxito evidenciado nos escalões de formação, sendo isso mais manifesto nas disciplinas cuja base de rendimento é sobretudo condicional.

Nos escalões infantil e iniciado, é no agrupamento das provas combinadas que se observa uma maior percentagem de atletas a destacar-se no escalão sénior. Pensamos que o carácter multilateral do treino para este agrupamento contribui consideravelmente para este resultado. Com efeito, parece-nos legítimo inferir que uma prática variada (corridas, saltos, lançamentos, bem como a prática de outras modalidades) não deve ser reprovada nem rejeitada, sobretudo durante as duas primeiras etapas do processo de formação desportiva - estádio de treino de base $(20,24,25)$.

$\mathrm{Na}$ situação inversa à do agrupamento das provas combinadas surge, no escalão infantil, o agrupamento das provas de marcha e no escalão iniciado, o agrupamento das provas de meio-fundo e fundo ( $0 \%$ e $5 \%$, respectivamente). Pelas características desses agrupamentos de provas, de entre as quais destacamos a estrutura de rendimento ancorada em capacidades condicionais (resistência), supomos que este resultado poderá evidenciar um acentuado nível de especialização imposto durante os escalões infantil e iniciado. Esta circunstância poderá ter condicionado negativamente o rendimento das atletas nos escalões superiores. A este respeito, Marques (19) preceitua que estas situações poderão resultar da aplicação de cargas de treino muito intensas, as quais predispõem para uma especialização precoce, ou do facto de os pressupostos básicos, ou seja, os fundamentos da prestação de alto nível, não terem sido desenvolvidos da forma mais adequada durante o processo de treino com os mais jovens.

Não obstante, é de considerar que o elevado nível de competitividade registado no agrupamento de meio-fundo e fundo poderá derivar numa maior dificuldade das atletas se imporem nos rks seniores.

No escalão juvenil, a maior percentagem (39\%) de surgimento nos rks seniores ocorre no agrupamento das provas de velocidade. Embora não disponhamos de informações sobre o passado desportivo das atletas em estudo, os resultados levam-nos a considerar que:

a) as mesmas realizaram nos escalões anteriores uma formação mais multilateral;

b) o processo de especialização nesse agrupamento de provas resulta de um trabalho contínuo e prolongado, no qual a carga de treino foi gradualmente individualizada;

c) a capacidade velocidade manifesta-se mais cedo que as demais capacidades motoras.

Por sua vez, nos agrupamentos marcha e lançamentos encontram-se os resultados mais baixos, respectivamente $0 \%$ e $9 \%$. Provavelmente, a acentuada especialização imposta desde cedo nestes agrupamentos de provas estará na origem destes resultados. De salientar ainda que, apesar do domínio da técnica se apresentar como parte indispensável para o êxito, a base de rendimento nestes agrupamentos é sobretudo condicional (resistência e força), capacidades estas de maturação mais tardia.

Ademais, as características morfológicas solicitadas no agrupamento lançamentos parecem condicionar uma prática quase exclusiva no mesmo. Como consequência, a especialização tornar-se-á inevitável. Todavia, é de relembrar que um lançador, particularmente enquanto jovem, deve privilegiar o desenvolvimento das capacidades técnico-coordenativas e da velocidade. Ainda que se constate a existência de muitos jovens a treinarem acentuada e exclusivamente para a prova em que obtêm melhores resultados, o bom senso manda adiar a especialização num único lançamento. A este respeito, Raposo (23), alerta para a necessidade de não haver precipitações, por forma a não se cometerem erros de especialização precoce.

De acordo com esta perspectiva consensual, Baz (4) e Schmolinsky (25), no caso concreto do atletismo, sugerem que a especialização desportiva se inicie por uma especialização multidisciplinar, isto é, centrada num agrupamento de provas comuns, como por exemplo a disciplina dos lançamentos. Acrescentam ainda que a opção por um agrupamento disciplinar não deve corresponder, desde logo, ao início do treino exclusivamente específico, pois a especialidade na qual o praticante se fixará deverá ser definida ao 
longo do seu desenvolvimento como atleta. Uma vez mais, o treino multilateral parece a via mais correcta, sendo responsável no futuro por resultados mais consistentes (20).

O percurso dentro do mesmo agrupamento de provas Analisado o percurso das atletas dentro do mesmo agrupamento de provas, verificámos que a percentagem de atletas que surgiram nos primeiros cinco lugares dos rks do escalão sénior se encontrava compreendida entre $5 \%$ (marcha) e $22 \%$ (saltos verticais). Genericamente, estes valores são inferiores, comparativamente aos registados quando não se teve a preocupação de analisar o percurso no mesmo agrupamento de provas. Ressalve-se as excepções observadas nos agrupamentos das provas de marcha (todos os escalões) e de lançamentos (escalões iniciado e juvenil). Estes resultados parecem reforçar o pressuposto segundo o qual as características destes agrupamentos de provas favorecem uma prática quase exclusiva dos mesmos. Permitem também inferir que a formação desportiva no agrupamento das provas de saltos verticais, comparativamente aos outros agrupamentos de provas, deverá ter sido sistematizada mais numa perspectiva de longo prazo. $\mathrm{O}$ facto de a base de rendimento dos saltos verticais ser essencialmente tecnico-coordenativa e não exclusivamente condicional, poderá favorecer a ocorrência deste resultado. Todavia, ainda se consideram reduzidos os valores registados.

Em particular, as percentagens de atletas nos primeiros cinco lugares do escalão sénior encontram-se compreendidas, para o escalão:

a) infantil, entre $0 \%$ (marcha) e $17 \%$ (saltos verticais);

b) iniciado, entre $5 \%$ (meio-fundo e fundo) e $23 \%$ (provas combinadas);

c) juvenil, entre $0 \%$ (marcha e provas combinadas) e $36 \%$ (velocidade).

O percurso nos rks das atletas em estudo, continua a revelar-se diferente para cada agrupamento de provas e para cada escalão. Confirma-se uma vez mais, à semelhança da análise anterior, que apenas uma minoria das atletas que se encontravam entre as melhores nos rks dos escalões infantil, iniciado e juvenil, durante 1986 a 1990, conseguiu confirmar no escalão sénior, no mesmo agrupamento de provas, o êxito evidenciado nos escalões de formação. Habitualmente, nestes escalões verifica-se uma elevada flutuabilidade dos atletas (entrada e saída de determinado agrupamento de provas ou modalidade), pelo que a submissão dos jovens a uma especialização precoce, salvo raras excepções, pouco contribui para que os mesmos alcancem a excelência desportiva no escalão sénior. Assim sendo, pensamos que a estruturação e delineamento da formação desportiva a longo prazo deverá ser uma preocupação permanente. Pois, com vista a alcançar a excelência desportiva, essa formação deve projectar-se no âmbito de uma visão de longo prazo (22), sendo tarefa do treinador adaptar o treino às principais particularidades evolutivas de cada idade (17). Filin (10) e Grosser et al. (12) reforçam este pressuposto salientando que os grandes resultados só poderão ser obtidos através de uma preparação contínua e cuidadosa de vários anos, programada de forma consciente $\mathrm{e}$ sistemática.

Por outro lado, o sistema de competições vigente parece continuar a contrariar o carácter multilateral pelo qual o treino dos mais jovens deve ser pautado, constituindo um círculo vicioso. Segundo Marques (18) são as competições que devem servir os propósitos da preparação desportiva, não o contrário. Embora exista consciência da necessidade de se adequar os programas competitivos às preocupações e necessidades formativas dos diferentes escalões do atletismo jovem, a sua concretização no terreno tem vindo a ser adiada. Portanto, o fomento de competições especializadas nos jovens continua a ser um problema muito actual e sem fim à vista, conduzindo à formação de rks e à obtenção de títulos distritais, zonais e nacionais. Por outro lado, os critérios vigentes de acesso ao percurso de alta competição, assim como as exigências colocadas para a acessibilidade aos estágios regionais e nacionais, continuam a basear-se nas performances, fomentando e favorecendo o elitismo e o resultado imediato.

Emerge assim de forma clara a necessidade de retardar a entrada dos jovens no sistema redutor de classificações.

Face a este quadro, exige-se que a prática desportiva (treino e competição) dos jovens apresente, obriga- 
toriamente, características diferentes das do adulto, quer no que concerne aos valores e às concepções de sucesso, quer às motivações para a prática e aos condicionamentos decorrentes da evidente imaturidade biológica e psicológica (3) dos sujeitos. Estamos convictos que só assim será possível inverter os baixos valores aqui registados.

\section{CONCLUSÕES}

Do estudo desenvolvido, extraem-se como principais conclusões:

a) Em termos globais, apenas uma reduzida percentagem dos atletas com bons resultados nas categorias menores sobressai posteriormente nos rks das categorias superiores.

- é no agrupamento das provas combinadas que uma maior percentagem de atletas dos escalões de formação surge nos primeiros cinco lugares do escalão sénior;

- no agrupamento das provas de marcha, apenas uma muito reduzida percentagem de atletas dos escalões de formação surge nos lugares considerados do escalão sénior.

- A percentagem de atletas dos escalões de formação que surge no escalão sénior é tanto menor quanto mais baixo é o escalão considerado.

De entre as atletas consideradas, apenas surgem nos rks do escalão sénior:

- $11 \%$ do escalão infantil;

- $13 \%$ do escalão iniciado;

- $26 \%$ do escalão juvenil.

b) As atletas posicionadas nos 5 primeiros lugares dos rks durante escalões de formação, em mais de um agrupamento, evidenciaram uma mais fértil evolução longitudinal nos rks (infantis - 17,8\%, iniciados - $27,7 \%$ e juvenis - $35,7 \%$ ), comparativamente com as que surgiam só num único agrupamento (infantis - $9,6 \%$, iniciados - $10,5 \%$ e juvenis $24,2 \%)$.

- os resultados mais baixos registam-se nos agrupamentos das provas de marcha, meio-fundo e fundo e lançamentos.

- os resultados mais elevados são observados nos agrupamentos das provas de saltos horizontais e provas combinadas.
Embora seja necessário aguardar mais alguns anos para se conhecer, na sua totalidade, o percurso das atletas em estudo, é já evidente que apenas um reduzido número de atletas conseguiu prolongar a sua carreira desportiva com uma constante presença nos lugares cimeiros dos rks.

Face a este quadro, é responsabilidade de todos os intervenientes no processo de formação desportiva diagnosticarem os problemas de que padece o Atletismo em Portugal. Ademais, julgamos ser urgente definir novas estratégias para o desenvolvimento do Atletismo nacional, a fim de formar atletas cada vez mais aptos e capazes de chegar à maturidade desportiva em condições de obterem melhores resultados, não só a nível nacional, mas sobretudo a nível internacional.

\section{Notas}

${ }^{1}$ Por exemplo, as provas de velocidade mais curtas para os infantis, iniciados e juvenis são respectivamente, $60 \mathrm{~m}, 80 \mathrm{~m}$ e $100 \mathrm{~m}$.

${ }^{2}$ Importa referir que a soma do número de atletas nos diferentes agrupamentos de provas é superior ao número total de atletas em estudo, uma vez que algumas atletas se encontravam em vários rks.

${ }^{3}$ O ganhar não é efémero. É positivo treinar os atletas para ganhar (mas não a qualquer preço). Todavia é bom e positivo preparar os jovens para perder e sobretudo para ver a derrota como um veículo e ponto de partida para organizar e reflectir o processo de treino no sentido de partir para tentar alcançar novas vitórias.

\section{CORRESPONDÊNCIA}

\section{Ramiro Rolim}

Faculdade de Ciências do Desporto

e de Educação Física

Universidade do Porto

Gabinete de Atletismo

Rua Dr. Plácido Costa, 91

4200.450 Porto, Portugal

rrolim@fcdef.up.pt 


\section{REFERÊNCIAS BIBLIOGRÁFICAS}

1. Adelino, J.; Vieira, J.; Coelho, O. (1999). Treino de jovens: $o$ que todos precisamos saber! Lisboa: Centro de Estudos e Formação Desportiva.

2. Añó, V. (1997). Planificación y organización del entrenamiento juvenil. Madrid: Gymnos Editorial.

3. Barata, A. (1999). O treino das capacidades condicionais em jovens desportistas. Treino Desportivo, Especial, 2:31-34.

4. Baz, I. (2000). Atletismo. Barcelona: INDE Publicaciones.

5. Bedoya, J. (1995). Entrenamiento temprano y captación de talento en el deporte. In D. Sánchez (Dir.) La iniciación deportiva y el deporte escolar. Barcelona: INDE Publicaciones.

6. Bompa, T. (1999). Planeamento a longo prazo: o caminho para a alta competição». In Seminário internacional - Treino de jovens: os caminhos do sucesso. Lisboa: Centro de Estudos e Formação Desportiva, 139-150.

7. Coelho, O. (1985). Actividade física e desportiva-aspectos gerais do seu desenvolvimento. Lisboa: Livros Horizonte.

8. Coelho e Silva, M. (1999). Treino desportivo com crianças e jovens. Treino Desportivo, Especial, 2: 2-11.

9. Feuillepain, C. (1997). Le devenir des jeunes. Revue de l'Association des Entraineurs Français Athlétisme, 145:5-16.

10. Filin, V. (1996). Desporto Juvenil - teoria e metodologia. Londrina: CID.

11. Garcia, R.; Rolim, R. (1994). A escola portuguesa de meiofundo e fundo. Rev. Atletismo, 156: 28-31.

12. Grosser, M.; Brüggemann, P.; Zintl, F. (1989). Alto rendimiento deportivo. Planificación y desarrollo. Barcelona: Ediciones Martínez Roca.

13. Hahn, E. (1988). Entrenamiento con niños. Barcelona: Ediciones Martínez Roca.

14. Knop, P.; Wylleman, P; Theeboom, M.; Martelaer, K.; Puymbroek, L.; Wittock, H. (1998). Clubes deportivos para niños y jóvenes. Andaluzia: Instituto Andaluz del Deporte.

15. Lima, T. (1981). Alta competição - Desporto de dimensões humanas? Lisboa: Livros Horizonte.

16. Lima, T. (1998). Uma perspectiva social na formação desportiva dos jovens. In Seminário Internacional - Treino de Jovens. Lisboa: Centro de Estudos e Formação Desportiva, 71-77.

17. Manno, R. (1992). Les bases de l'entraînement sportif. Paris: Editions Revue E.P.S.

18. Marques, A. (1991). A especialização precoce na preparação desportiva. Treino Desportivo, 2a série, 19:9-15.

19. Marques, A. (1998). Crianças e adolescentes atletas: entre as escola e os centros de treino... entre os centros de treino e a escola! In Seminário Internacional - Treino de Jovens. Lisboa: Centro de Estudos e Formação Desportiva, 17-30.

20. Matvéiev, L. (1990). O processo de treino desportivo. Lisboa: Livros Horizonte.

21. Mesquita, I. (1997). Pedagogia do treino - a formação em jogos desportivos colectivos. Lisboa: Livros Horizonte.

22. Ramlow, J. (1992). El desarrollo a largo plazo de las destrezas técnicas. Stadium, 152:147.

23. Raposo, A. (2000). Planificación y organización del entrenamiento deportivo. Barcelona: Editorial Paidotribo.

24. Rolim, R. (1998). Contributo para o estudo do treino de meio-fundo/fundo de atletas jovens em Portugal. Dissertação de doutoramento. Faculdade de Ciências do Desporto e de Educação Física da Universidade do Porto (não publicado)
25. Schmolinsky, G. (1992). Atletismo. Lisboa: Editorial Estampa.

26. Suslov, F. P.; Nikitunskin, V. G.; Gomes, A. (1995). Atletismo: preparação de corredores juvenis nas provas de meio fundo. Londrina: CID.

27. Verdugo, M.; Leibar, X. (1997). Entrenamiento de la resistencia. Madrid: Gymnos Editorial Deportiva. 